\title{
Continuous subcutaneous insulin infusion (CSII) does not prevent progression of proliferative and preproliferative retinopathy
}

\author{
PAUL M. LAWSON, ${ }^{1}$ MALCOLM C. CHAMPION ${ }^{2}$ CHRISTOPHER CANNY, \\ RONALD KINGSLEY,' MICHAEL C. WHITE,' JOHN DUPRÉ, ${ }^{2}$ AND \\ EVA M. KOHNER ${ }^{1}$
}

From the 'Department of Medicine, Royal Postgraduate Medical School, Hammersmith Hospital, Ducane Road, London W12, and the ${ }^{2}$ Departments of Medicine and Ophthalmology, University Hospital, London, Ontario, Canada

SUMmaRY Twelve patients with either proliferative or preproliferative diabetic retinopathy were managed by continuous subcutaneous insulin infusion (CSII) for periods of from 4 to 19 months. Despite the excellent control of blood sugar achieved by this technique out of the 24 eyes 20 deteriorated, with initiation of neovascularisation in 12 eyes and worsening of new vessels in 8 eyes. Thus photocoagulation remains the treatment of choice for such cases.

The role of good diabetic control in the prevention and management of diabetic microvascular complications is one of the central issues in diabetes. Although most diabetologists believe that poor control is related to the development of microvascular lesions, there is little objective evidence that improving control benefits established complications.' Recent advances, such as technique of administering insulin and methods for assessing the degree of control obtained, have made this difficult subject more amenable to examination.

Since the introduction of ambulatory continuous insulin infusions at least 2 case reports have been published $^{23}$ which indicate the possibility of marked improvement in both proliferative and preproliferative retinopathy after short periods of good blood sugar control. To clarify these claims this study looked at the effect of the good control obtained by continuous subcutaneous insulin infusion (CSII), applied for periods of from 4 to 19 months, on the eyes of 12 diabetic patients who had either proliferative or preproliferative retinopathy.

\section{Patients and methods}

Eight diabetic patients from the Hammersmith Correspondence to Dr Paul Lawson, Lower Medical Corridor, Hammersmith Hospital, Ducane Road, London W12.
Hospital, London, England, and 4 patients from the University Hospital, London, Ontario, Canada, were managed by CSII for periods of from 4 to 19 months. Details of each patients are given in Tables 1 and 2 .

Three patients had proliferative retinopathy in both eyes, 6 had preproliferative retinopathy in both eyes, and 3 had preproliferative retinopathy in one eye and proliferative in the other at the start of CSII therapy. Each patient had a full ophthalmological examination including assessment of best possible visual acuity, fundus examination, and retinal photography. Fluorescein angiography was performed in most cases. Preproliferative retinopathy was diagnosed from retinal photography and was defined as the presence of 3 or more of the following abnormalities in at least 2 photographic fields: $(a)$ multiple large blot haemorrhages; $(b)$ multiple cotton-wool spots; $(c)$ intraretinal microvascular abnormalities (IRMA); (d) venous abnormalities (including dilatation, beading, loop formation, and reduplication); $(e)$ arterial sheathing and white lines replacing normal vessels. Panretinal ablative photocoagulation (PRP) was applied for new vessels when considered necessary. Usually flat peripheral new vessels were left, and closely followed up until it was apparent that they were worsening. Disc or forward peripheral new vessels were, however, always treated by PRP as soon as possible. 
Table 1 Details of patients

\begin{tabular}{|c|c|c|c|c|c|c|c|}
\hline \multirow[t]{2}{*}{ Patient } & \multirow[t]{2}{*}{ Age $(y r)$} & \multirow{2}{*}{$\begin{array}{l}\text { Duration of } \\
\text { diabetes } \\
(y r)\end{array}$} & \multirow{2}{*}{$\begin{array}{l}H b A_{1} \% \\
\text { before CSII }\end{array}$} & \multicolumn{2}{|c|}{ Control on CSII } & \multirow{2}{*}{$\begin{array}{l}\text { Other medical } \\
\text { problems }\end{array}$} & \multirow[t]{2}{*}{ Comments } \\
\hline & & & & $H b A_{1} \%$ & Mean sugar $\pm S D$ mmol/ 1 & & \\
\hline 1 & 47 & 14 & $* 9 \cdot 2$ & $7 \cdot 5$ & $6 \cdot 2 \pm 0 \cdot 8$ & Peripheral neuropathy & Good control \\
\hline 2 & 29 & 20 & $* 13.4$ & $8 \cdot 2$ & $8 \cdot 5 \pm 2 \cdot 9$ & Nil & Good control \\
\hline 3 & 16 & 14 & $* 15 \cdot 6$ & $7 \cdot \overline{5}$ & $5 \cdot 1 \pm 0 \cdot 6$ & $\begin{array}{l}\text { Proteinuria } \\
\text { hypertension }\end{array}$ & $\begin{array}{l}\text { Ketoacidosis at one } \\
\text { month }\end{array}$ \\
\hline 4 & 20 & 18 & $*$ & 7 & $5 \cdot 7 \pm 1 \cdot 4$ & Nil & Good control \\
\hline 5 & 42 & 24 & $* 7$ & 7 & $5 \pm 0 \cdot 5$ & $\begin{array}{l}\text { Nephropathy } \\
\text { hypertension }\end{array}$ & Good control \\
\hline 6 & 34 & 19 & ${ }^{*} 12 \cdot 5$ & 10 & $8 \cdot 6 \pm 2 \cdot 8$ & Anxiety & Moderately good control \\
\hline 7 & 39 & 20 & ${ }^{*} 12 \cdot 3$ & $8 \cdot 8$ & $8 \pm 3.9$ & Proteinuria & $\begin{array}{l}\text { Asymptomatic } \\
\text { hypoglycaemia }\end{array}$ \\
\hline 8 & 21 & 16 & $+12 \cdot 6$ & $12 \cdot 6$ & $7 \cdot 5 \pm 3$ & Proteinuria & Moderate control \\
\hline 9 & 22 & 18 & $+18 \cdot 2$ & $14 \cdot 9$ & $9.9 \pm 3 \cdot 7$ & Nephropathy & Poor compliance \\
\hline 10 & 23 & 11 & - & - & $5 \cdot 8 \pm 1 \cdot 6$ & Nil & Good control \\
\hline 11 & 29 & 13 & $+11 \cdot 4$ & $9 \cdot 7$ & $6 \cdot 1 \pm 2 \cdot 5$ & $\begin{array}{l}\text { Nephropathy } \\
\text { neuropathy }\end{array}$ & Good control \\
\hline 12 & 18 & 12 & - & - & $5 \cdot 9 \pm 1 \cdot 1$ & Nil & Good control \\
\hline
\end{tabular}

*Normal range 5·2-8.6.

†Normal range $5 \cdot 4-10 \cdot 2$.

$\mathrm{SD}=$ standard deviation.

Eleven of the patients were insulin-dependent diabetics (IDDM), and one was not insulindependent (NIDDM) (patient 1), this classification being based on the patient's age, duration of diabetes, type of therapy, and $\mathrm{C}$ peptide estimation in 6 cases. Two patients were mildly hypertensive, and both received therapy to return this to normal.

CSII was given with the Mill Hill Infuser model 1001 HM (Muirhead Medical Products Ltd, London SE25). The method of delivery was essentially that described by Pickup et al. ${ }^{4}$ with approximately $50 \%$ of the dose given as a continuous background infusion and the remainder as boluses before meals.
Patients monitored their own blood sugar (Dextrostix Ames Ltd, read in either a Glucochek or Glucometer) before meals and before bed on at least alternate days, and additional tests were taken 90 minutes after meals to check the effect of the premeal bolus.

The degree of control each patient achieved was assessed from the detailed records of the home capillary blood sugars (a mean blood sugar being calculated from at least 50 results per month) and monthly $\mathrm{HbAl}$ measurements (Biorad Kit Microcolumn method at the Hammersmith Hospital and Alberti Colourimetric method at University

Table 2 Outcome of retinopathies after CSII

\begin{tabular}{|c|c|c|c|c|c|c|c|c|c|c|c|}
\hline \multirow[t]{3}{*}{ Patient } & \multicolumn{4}{|c|}{ Retinopathy } & \multirow{3}{*}{$\begin{array}{l}\text { Duration of } \\
\text { CSII (months) }\end{array}$} & \multicolumn{4}{|c|}{ Retinopathy outcome on CSII } & \multirow{2}{*}{\multicolumn{2}{|c|}{$\begin{array}{l}\text { Photocoagulation } \\
\text { (months after start } \\
\text { of CSII) }\end{array}$}} \\
\hline & \multicolumn{2}{|c|}{ Initial grade } & \multicolumn{2}{|c|}{ Visual acuity } & & \multicolumn{2}{|l|}{ Grade } & \multicolumn{2}{|c|}{ Visual acuity } & & \\
\hline & Reye & Leye & Reye & Leye & & Reye & Leye & Reye & Leye & Reye & Leye \\
\hline 1 & PP & PP & $6 / 6$ & $6 / 6$ & 18 & $\mathbf{P}$ & $\mathbf{P}$ & $6 / 9$ & $6 / 6$ & 4 & 7 \\
\hline 2 & $\mathbf{P}(\mathbf{S})$ & $\mathbf{P}(\mathbf{S})$ & $6 / 9$ & $6 / 6$ & 4 & $\mathrm{P}(\mathrm{S})+\mathrm{VH}$ & $\mathrm{P}(\mathrm{S})+\mathrm{VH}$ & CF & CF & $1^{*}$ & $1^{*}$ \\
\hline 3 & PP & PP & $6 / 6$ & $6 / 6$ & 15 & $\mathrm{P}(\mathrm{F})$ & $\mathrm{P}(\mathrm{F})$ & $6 / 9$ & $6 / 6$ & 2 & 2 \\
\hline 4 & $P(E)$ & $P(E)$ & $6 / 5$ & $6 / 5$ & 11 & $\mathbf{P}$ & $\mathbf{P}$ & $6 / 5$ & $6 / 5$ & 7 & 9 \\
\hline 5 & PP & PP & $6 / 6$ & $6 / 6$ & 15 & PP & $\mathbf{P}$ & $6 / 6$ & $6 / 6$ & None & 10 \\
\hline 6 & PP & $P(E)$ & $6 / 5$ & $6 / 5$ & 6 & PP & $\mathbf{P}$ & $6 / 5$ & $6 / 5$ & None & 2 \\
\hline 7 & $\mathbf{P}$ & PP & $6 / 6$ & $6 / 6$ & 6 & $\mathbf{P}$ & PP & $6 / 6$ & $6 / 6$ & \multicolumn{2}{|c|}{ Before CSIINone } \\
\hline 8 & PP & PP & $6 / 7 \cdot 5$ & $6 / 7 \cdot 5$ & $3 \cdot 5$ & $\mathbf{P}$ & $\mathbf{P}$ & $6 / 15$ & $6 / 15$ & 4 & 4 \\
\hline 9 & PP & PP & $6 / 6$ & $6 / 6$ & 7 & $\mathbf{P}$ & $\mathbf{P}$ & $6 / 6$ & $6 / 6$ & 7 & 7 \\
\hline 10 & $\mathbf{P}$ & PP & $6 / 18$ & $6 / 6$ & 19 & $\mathrm{P}+\mathrm{VH}$ & $\mathrm{P}+\mathrm{VH}$ & $6 / 7 \cdot 5$ & HM & Before & 3 \\
\hline 11 & PP & PP & $6 / 6$ & $6 / 7 \cdot 5$ & 19 & $\mathrm{P}+\mathrm{VH}$ & $\mathrm{P}+\mathrm{MO}$ & $\mathrm{CF}$ & CF & 9 & 9 \\
\hline 12 & $\mathbf{P}$ & $\mathbf{P}$ & $6 / 6$ & $6 / 7 \cdot 5$ & 4 & $\mathbf{P}$ & $\mathbf{P}$ & $6 / 6$ & $6 / 9$ & $1^{*}$ & $2^{*}$ \\
\hline
\end{tabular}

$\mathrm{P}=$ proliferative $. \mathrm{PP}=$ preproliferative $.(\mathrm{S})=$ severe $.(\mathrm{E})=$ early. $(\mathrm{F})=$ florid $. \mathrm{VH}=$ vitreous haemorrhage $. \mathrm{MO}=\mathrm{macular}$ oedema. $\mathrm{CF}=$ counting fingers. $\mathrm{HM}=$ hand movements.

*Photocoagulation also preceding CSII 


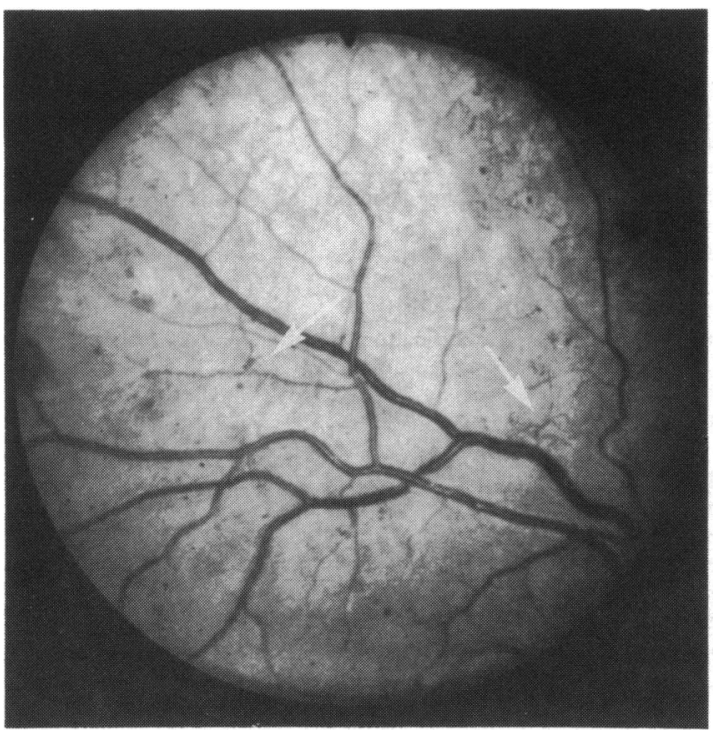

Fig. 1A

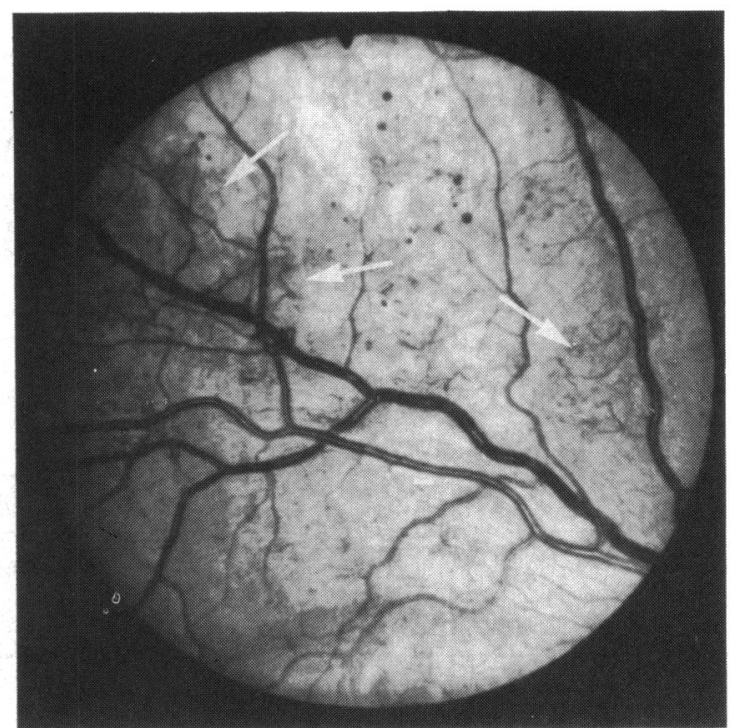

Fig. 1B

Fig. 1A Patient 4, right eye superior temporal region, showing early new vessels (arrows) before start of CSII treatment. B Marked development of new vessels in the same area after 7 months of CSII treatment.

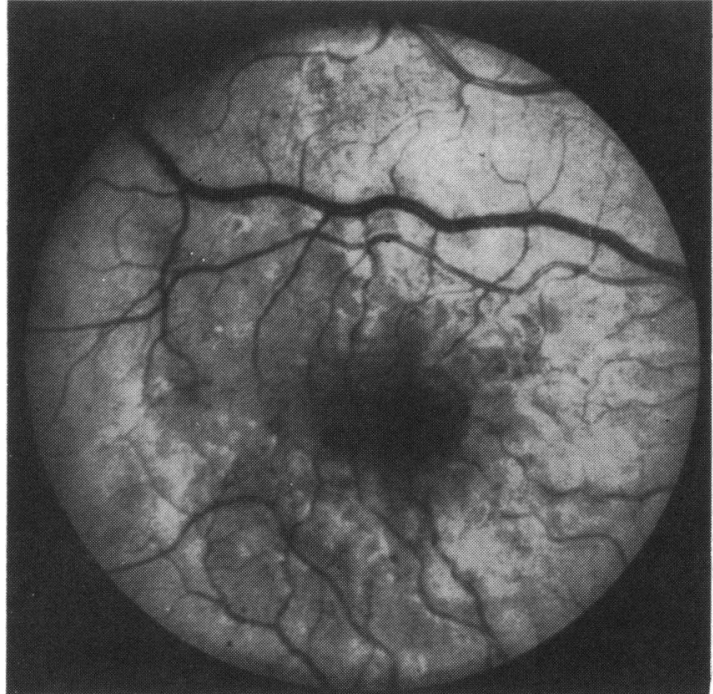

Fig. 2A

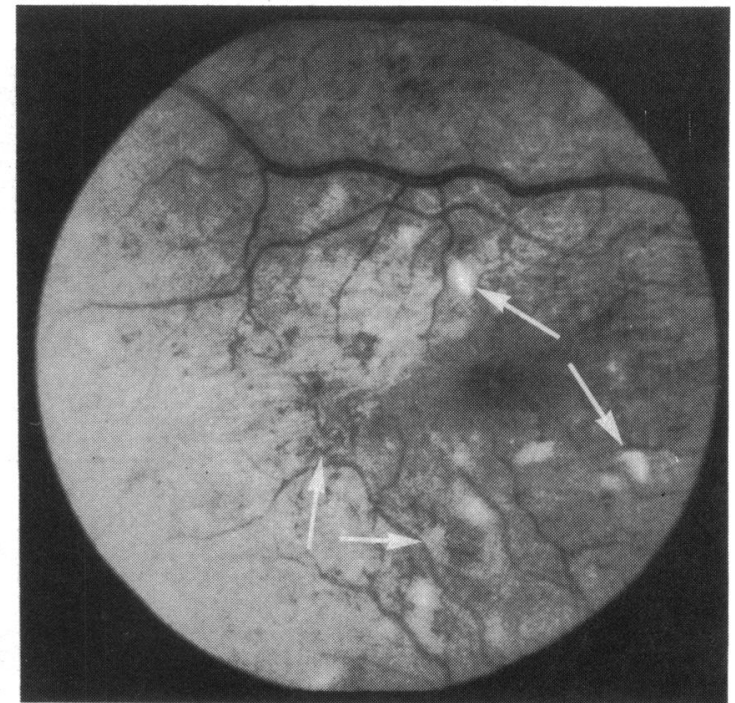

Fig. 2B

Fig. 2A Patient 3, right macula before start of CSII. B After 2 months of CSII treatment, showing development of multiple cotton-wool spots (upper arrows), and multiple areas early new vessels (lower arrows).

Hospital). Normoglycaemia was aimed for in 10 of the patients. In the other 2 the best possible control without hypoglycaemia was sought-in one patient because she lived on her own and was prone to hypoglycaemia and in the other because of asymptomatic hypoglycaemia as a result of autonomic neuropathy. Close contact was kept by a physician with all patients to give advice about optimising blood sugar control and to give help with any technical or other problems from the method. 
The study was approved by the ethics committees of both hospitals and informed consent was obtained from all patients.

\section{Results}

The outcome of the retinopathy for each patient is summarised in Table 2. If each patient is taken as having 2 independent eyes, initially there were 9 prolifreative and 15 preproliferative eyes. Of the 9 proliferative eyes 2 were severe, with extensive fibrosis, 4 were moderately severe, with active disc new vessels, and 3 had very early peripheral new vessels.

Of the 9 proliferative eyes 6 received photocoagulation therapy before the application of CSII; of these, 5 progressed further, with vitreous haemorrhage in 3 and advancement of neovascularisation in 2 despite from 4 to 9 months of CSII. The sixth eye did not change significantly after 6 months of CSII. In the 3 eyes not treated initially because they had only very early peripheral new vessels, neovascularisation advanced such that photocoagulation had to be applied after periods of 2,7 , and 9 months of CSII (Fig. 1A,B).

Of the 15 preproliferative eyes 12 had developed new vessels ( 4 disc, 8 peripheral) after from 2 to 10 months of CSII. In 3 of these vision deteriorated, owing to vitreous haemorrhage in 2 and macular oedema in the other one. In one (patient 3), a 16year-old pubertal boy, progression from preproliferative to florid proliferative retinopathy occurred in both eyes within the first 8 weeks of CSII (Fig. 2A,B), during which period he had an episode of ketoacidosis due to an abscess developing at his injection site. In the other 3 preproliferative eyes, although neovascularisation did not develop, there was no change in the retinal appearance after CSII for periods of 6 to 15 months.

In 8 patients the control obtained was consistent with the degree of control aimed at with CSII, that is, most blood sugars $<8 \mathrm{mmol} / \mathrm{l}$ and $\mathrm{HbA}_{1}$ in the upper range of normal or just above (Table 1). Of the other 4,2 showed considerable improvement from previous therapy, although near-normalisation of blood sugar was not achieved, and in 2 the degree of control appeared unchanged.

In summary, out of 24 eyes 20 definitely progressed with either initiation or further development of neovascularisation. No eyes showed any improvement.

\section{Discussion}

The finding that proliferative and preproliferative retinopathy do not improve and in most cases deteriorate despite the achievement of good blood sugar control through CSII is not altogether surprising. The reason lies in the severity of the underlying retinal ischaemic damage in these retinopathies. The common factor in all conditions which develop retinal neovascularisation, such as retinal vein occlusion, sickle cell disease, and diabetes, is large areas of retinal nonperfusion, ${ }^{5}$ which are thought to be the stimulus to the new vessels. Even if good blood sugar control does have a therapeutic effect in reducing further development of such areas, it is unlikely that it would be enough on its own to stop this stimulation.

It is expected that most proliferative and preproliferative retinopathies deteriorate, and perhaps each case in this study would have deteriorated to a similar extent with conventional insulin therapy. However, it has been reported that when blood sugar was improved in 4 adolescent diabetics with stunted growth $^{6}$ there was rapid deterioration in retinopathy, and this along with the overall extent of deterioration in the cases reported here raises the possibility of a detrimental effect of CSII treatment. Several mechanisms could result in deterioration. Firstly, the somatomedin levels may have an effect, as it has been shown that improved control by CSII increases somatomedin from previously subnormal levels found in poorly controlled diabetes while it reduces growth hormone from previously high levels. ${ }^{7}$ Potentially this change in balance could result in new vessel stimulation. Secondly, the rapid development of cotton-wool spots as seen in one patient suggests a worsening of retinal ischaemia. This could occur if retinal blood flow was reduced, which is in fact very likely to be the case, for it is known that retinal blood flow is increased in poorly controlled diabetes ${ }^{8}$ and it has been shown that improving control by CSII reduces the perfusion-related high glomerular filtration rate found in diabetics towards normal. ${ }^{9} \mathrm{~A}$ third potentially damaging effect which has been suggested is chronic hypoglycaemia; however, this did not occur in any of the patients here. Finally in the case of adolescents the change in hormonal balance which occurs with the onset of puberty might be involved.

The study presented here confines itself to advanced retinopathy and does not give information about the effect of improving control on early microvascular disease or its potential for prevention of such complications. Studies are at present underway looking at CSII given to patients with mild background retinopathy, and already it has been shown that tightening control of the diabetes by CSII improves tests of retinal function, including a lessening of vascular leakage. ${ }^{910}$ It has not yet been shown if this will be reflected by an eventual improvement or lack of progression in retinal 
appearance. In conclusion it has been shown that improvement of blood sugar control by CSII is not an effective treatment for proliferative and preproliferative diabetic retinopathy. Hence at present photocoagulation, which has been shown to be effective, ${ }^{11}$ remains the only treatment available. The question of a potentially harmful effect of CSII on such severe retinopathies has been raised. A potentially beneficial value of good control on early forms of retinopathy, and in the prevention of microvascular disease, is not excluded by these findings.

P.M.L. was supported by a Kroc Foundation grant.

\section{References}

1 Tchobroutsky G. Relationship of diabetic control to development of microvascular complications. Diabetologia 1978; 15: $143-52$

2 White MC, Kohner EM, Pickup JC, Keen H. Reversal of diabetic retinopathy by continuous subcutaneous insulin infusion: a case report. Br J Ophthalmol 1981; 65: 307-11.

3 Irsigler K, Kritz H, Najemnik C, Freyler H. Reversal of florid proliferative diabetic retinopathy through achievement of normo- glycaemia over five months by means of a portable insulin-dosage apparatus. Wien Klin Wochenschr 1980; 92: 270-6.

4 Pickup JC, Keen H, Parsons JA. Alberti KGMM. Continuous subcutaneous insulin infusion: an approach to achieving normoglycaemia. Br Med J 1978; i: 204-7.

5 Laatikainen L, Kohner EM. Fluorescein angiography and its prognostic significance in central retinal vein occlusion. $\mathrm{Br} J$ Ophthalmol 1976; 60: 411-8.

6 Daneman D, Drash AL, Lobes LA, Becker DJ, Baker LM, Travis LB. Progressive retinopathy with improved control in diabetic dwarfism (Mauriac's syndrome). Diabetes Care 1981; 4: $360-5$.

7 Tamborlane MV, Hintz RL, Bergman M, Genel M, Felig P. Sherwin RS. Insulin-infusion pump treatment of diabetes. Influence of improved metabolic control on plasma somatomedin levels. N Engl J Med 1981; 305: 303-11.

8 Kohner EM, Hamilton AM, Saunders S, Sutcliffe BA, Bulpitt CJ. The retinal blood flow in diabetes. Diabetologia 1975; 11: 27-33.

9 Steno Study Group. Effect of 6 months of strict metabolic control on eye and kidney function in insulin-dependent diabetics with background retinopathy. Lancet 1982; i: 122-24.

10 White NH, Waltman SR, Krupin T, Santiago J. Reversal of abnormalities in ocular fluorophotometry in insulin-dependent diabetes after five to nine months of improved metabolic control. Diabetes 1982; 31: 80-5.

11 Diabetic Retinopathy Study Research Group. Preliminary report on the effects of photocoagulation. Am J Ophthalmol 1976; 81: 383. 